\title{
Consumer Spending and Customer Satisfaction: Untying the Knot
}

\author{
Peter Sephton \\ School of Business, Queen's University, Kingston, ON, Canada K7L 3N6 \\ Correspondence should be addressed to Peter Sephton, psephton@business.queensu.ca
}

Received 1 August 2011; Accepted 23 October 2011

Academic Editor: Donald Lien

Copyright () 2012 Peter Sephton. This is an open access article distributed under the Creative Commons Attribution License, which permits unrestricted use, distribution, and reproduction in any medium, provided the original work is properly cited.

The recession of 2007-2009 has led to renewed interest in forecasting discretionary consumer spending and whether marketing variables contain predictive content. Using the ACSI customer satisfaction index and both linear and nonlinear methods, this note suggests the index fails to enhance our understanding of the temporal evolution of discretionary spending.

\section{Introduction}

Throughout 2009, there was renewed interest in forecasting business cycle turning points as the economy struggled with the forces of creative destruction. As financial markets began a period of sustained growth, market-watchers wondered aloud whether recovery was in sight or if the upward trend was just a "dead cat bounce." How would we know when consistent growth had returned? When would discretionary spending begin to rise and how should businesses react? Should firms raise production now in anticipation of higher levels of demand or wait until stockouts signalled the worst was over and an increase in production was warranted? Put differently, could marketing variables such as customer satisfaction help predict discretionary spending? Consumer confidence and customer satisfaction sometimes appear to dominate the effects of variables traditionally thought to drive consumption. Could measures of customer satisfaction help predict consumption above and beyond the usual panoply of economic data on disposable income and debtservice ratios?

Fornell et al. [1] reported preliminary success in using measures of satisfaction to predict discretionary expenditures, extending related work by Gupta and Zeithaml [2] on linking satisfaction to financial performance and Keiningham et al. [3] on the relationship between satisfaction and customer retention and recommendation. However, Fornell et al. [1] employ an ad hoc specification involving nonlinearities without sufficient testing to ensure that their model is properly specified. The purpose here is to deter- mine whether there are long-run linear and/or nonlinear relationships linking satisfaction and other economic data to discretionary spending. If so, forecasting models can be improved by incorporating the restrictions implied by these relationships. To anticipate the empirical results, perhaps, unfortunately, customer satisfaction has little, if any predictive content for discretionary spending. The search for an effective forecasting model linking measures of marketing performance to discretionary consumption continues.

The next section contains single equation test results that indicate there is little merit in considering satisfaction when modeling the determinants of discretionary spending whereas a systems approach to testing provides some evidence that satisfaction "matters." Tests for threshold cointegration, which allows asymmetric adjustment back to the long-run relationship, uniformly reject the view that satisfaction measures affect consumption. A nonlinear nonparametric approach provides clear evidence of threshold effects that can improve marketers' abilities to predict spending, albeit with no input from measures of customer satisfaction.

\section{Cointegration and Error Correction Models}

The central question here is whether measures of customer satisfaction are cointegrated with discretionary consumption spending. If so, our forecasting models should incorporate those effects, along with those coming from the variables traditionally considered to be primary determinants of 
consumption. To that end, data on real personal disposable income and real personal consumption expenditures were obtained from the Bureau of Economic Analysis. Real discretionary personal expenditures (DCEs) are constructed as total expenditures less spending on housing, food, and medical care. The American Customer Satisfaction Index (ACSI) was obtained from the ACSI website, http://www.theacsi.org/, while data on the all-items CPI, the debt-service ratio (DSR), and consumer credit outstanding was obtained from the St. Louis Federal Reserve Bank's FRED database. All series span 1994 Q4 through 2008 Q3, with monthly data adjusted to quarterly figures by taking monthly averages. Real credit outstanding was constructed by deflating outstanding credit by the CPI.

The current financial crisis was precipitated by an overreliance on credit-particularly revolving lines of credit-in anticipation of continually higher housing prices. The collapse of those prices and the associated effects on consumer credit outstanding suggest that it might be interesting to break total outstanding consumer credit into both revolving and nonrevolving credit to determine whether discretionary expenditures are more highly related to one form of credit than the other. To that end, both real outstanding consumer credit based on revolving (CCR) and nonrevolving credit (CCNR) will be included in the analysis.

The specification of the cointegrating regression is given by (1). Note that at this stage there are no asymmetries in the relationship and, if the series are cointegrated, each must individually be integrated of the same order (i.e., they must each be difference stationary):

$$
\begin{aligned}
\ln (\mathrm{DCE})_{t}= & \beta_{1}+\beta_{2} \ln (\mathrm{SAT})_{t}+\beta_{3} \ln (\mathrm{RPDI})_{t} \\
& +\beta_{4} \ln (\mathrm{CCR})_{t}+\beta_{5} \ln (\mathrm{CCNR})_{t} \\
& +\beta_{6} \ln (\mathrm{DSR})_{t}+\varepsilon_{t} .
\end{aligned}
$$

Unit root and stationarity tests indicated that each series integrated of order one. For brevity, those test results will not be reported.

Given there are six variables under examination, there could be as many as five cointegrating vectors. The next section begins with single-equation tests of cointegration as well as estimates based on the Johansen and Juselius [4] methodology. Given the empirical findings, this is followed by a single equation analysis to determine whether there is asymmetric adjustment in the system. A nonparametric approach using nonlinear methods follows.

\section{Empirical Results}

The cointegration analysis will employ data spanning 1994 Q4 to 2008 Q3. Engle and Granger [5] introduced the concept of cointegration and provided one of the first tests in the single equation environment. Their test examines the null hypothesis of noncointegration by testing the residual from the cointegrating regression to see whether it contains a unit root. To save space, I will simply report that, for tests including a constant or a constant and a trend and for lag adjustments between zero and four (and even up to eight), one cannot reject the null hypothesis of a unit root at the five percent level of significance. This suggests the series are not cointegrated and there is no meaningful long-run link between real discretionary consumption and the other series, a result that is at odds with what one might expect. Closer inspection of the cointegrating regression indicates that some variables should be dropped from the system. Consider (2)

$$
\begin{aligned}
\ln (\mathrm{DCE})_{t}= & 2.1699-0.1607 \ln (\mathrm{SAT})_{t}+0.694 \ln (\mathrm{RPDI})_{t} \\
& +0.597 \ln (\mathrm{CCR})_{t}(3.77)(-1.08)(5.56)(6.02) \\
& -0.0788 \ln (\mathrm{CCNR})_{t}+0.0224 \ln (\mathrm{DSR})_{t} \\
& \times(-0.49)(0.34)
\end{aligned}
$$

where $t$-statistics based on robust standard errors appear in parentheses. Clearly, the only variables that should be retained are real personal disposable income and revolving consumer credit outstanding. Customer satisfaction, nonrevolving outstanding consumer credit, and the debt-service ratio have coefficients that are statistically insignificantly different from zero at the five percent level. Deleting these series from the cointegrating regression and repeating the test do not qualitatively affect inference, at or about the five percent level of significance, independently of lag length and deterministic components. It would appear that singleequation cointegration analysis is particularly unhelpful in modeling discretionary spending.

However, the systems approach to cointegration testing does indicate the six variables are cointegrated with one cointegrating vector (at the five percent level of significance, given a lag length of two). The associated error correction models (excluded for brevity) suggest that real personal disposable income and the ACSI index are weakly exogenous in that they do not help restore the system back to its attractor. These findings are intuitively pleasing, since it might be reasonable to assert that the ACSI index and real disposable income can be taken to be given. The ACSI index measures customer satisfaction, and while (in natural logarithms) its correlation with real GDP is roughly 0.61 , one might assert that the causal link is from real GDP to the ACSI index, with adjustment in real GDP rather than customer satisfaction, absent psychological and international and industry-specific effects such as those identified by Johnson et al. [6]. Similarly, personal disposable income is not under the direct control of most consumers-it is taken as given. Discretionary spending and measures of outstanding consumer credit should respond to any disequilibrium in the system, as should the debt-service ratio if it is related to macroeconomic conditions, which are, in part, determined by discretionary consumer expenditures and their effects on inflation-and as the central bank's policy response filters through the term structure of interest rates.

These results provide a role for using the ACSI index in setting marketing plans, but they fail to provide the asymmetric or threshold effects identified by Fornell et al. [1]. 
Asymmetric adjustment in the error correction mechanism was examined by Enders and Siklos [7]. In essence, when testing whether the residual from the cointegrating regression has a unit root or not (the Engle-Granger null of noncointegration), Enders and Siklos [7] allow for asymmetry; positive and negative (or above and below a threshold) departures from the attracter garner different patterns of adjustment back to equilibrium. They specified threshold autoregressive (TAR) and momentum threshold autoregressive (MTAR) models to test whether there was evidence of asymmetric adjustment, extending previous work by Balke and Fomby [8].

Cook [9] provided an improved TAR and MTAR testing regime that has better statistical properties than the original Enders and Siklos [7] approach due to the fact that the series are initially "GLS detrended" to eliminate deterministic components. Application of the Cook [9] tests failed to identify any evidence of threshold cointegration, either around a set threshold of zero or around a consistentthreshold chosen using the methods outlined in Chan [10]. This was true for any lag length considered and for both detrending constant and/or trend deterministics from the series. It was also true for the non-GLS detrended versions of the Enders and Siklos [7] TAR and MTAR tests. It would appear that there is little evidence in favor of asymmetric adjustment in the linear relationship between discretionary spending and its primary determinants.

\section{Nonlinear Cointegration}

While the multivariate cointegration test identified one cointegrating vector, using linear models, there is little evidence of threshold effects in the link between discretionary spending and its determinants. It seems appropriate then to consider nonlinear relationships to see whether they can provide additional insight.

Nonlinear cointegration has been examined by many authors (see, e.g., Bierens [12] and Breitung [13]). The methods of Sephton [14] seem most appropriate for the present analysis. Multivariate adaptive regression spline (MARS) models due to Friedman [15] are used to fit the nonlinear cointegrating regression to which the Engle-Granger cointegration test is applied. The MARS routine finds the optimal transformations of series and their interactions by creating a large set of basis functions - transformations of series above and below certain threshold values, or knotsfitting a relatively large model and then paring down the size of the fitted relationship based on a variation of a degrees of freedom adjusted sum-of-squared residuals metric. The final model can be linear in the transformed variables or it can involve products of basis functions relating several variables so that both additive and interactive effects of series on the target variable are allowed. Plots of the transformed series show the contributions of the basis functions to the fitted model, which is determined by an ordinary regression of the dependent variable against the various basis functions chosen by the routine.
MARS models have been applied successfully in across a variety of disciplines, in economics, pharmaceuticals, customer relationship management, and other intensive datamining applications (see http://www.salford-systems.com/ and the section "Product Overview" for over fifty published examples and applications across the natural and social sciences and management). One could consider the MARS routine as the optimal search for thresholds or knots amongst the various predictors of discretionary spending. Indeed, a model that allows two-way multiplicative interactions is in the spirit of Fornell et al. [1], since they allowed changes in customer satisfaction to interact with the debt-service ratio. A finding of nonlinear cointegration would lead to the specification of an error correction model using the transformed variables relative to their threshold values and the error correction term. Such a model would endogenize the search for threshold cointegration.

The MARS routine contains a large number of "tuning parameters" which set the size of the largest model (from which the optimal model is chosen), the order of variable interaction, and the penalty function (related to the sumof-squared residuals) used to choose the final specification. As part of the output one finds the relative importance of each variable in the final model, measures of goodness of fit, and plots of the optimal transformations of the series. Table 1 presents the estimated model characterizing the nonlinear cointegrating regression. There are seven basis functions involving all of the predictors except the customer satisfaction index. Revolving credit has a unique effect onto itself while there are interactions between the debt-service ratio and nonrevolving credit, and personal disposable income and nonrevolving credit.

MARS is a very flexible algorithm and the fact that it chose a model that excludes the ACSI index suggests the index has no power to predict discretionary spending. Indeed, one of the challenges of nonparametric routines such as MARS is that there is a potential to overfit the relationship by building a model that is "too" large. Experimentation with the model parameters to find a specification that did include the ACSI index required a very large model that was clearly overparameterized given the dataset only includes 56 observations, which is already relatively short and may strain the data-mining capabilities of the MARS algorithm.

We now examine two tests for whether the series are cointegrated. The first is based on the cointegrating regression residuals to see if the variables which were chosen by the routine provide evidence of nonlinear cointegration. Sephton [14] provides estimates of critical values of the Engle and Granger [5] approach to testing for cointegration in MARS models using the unit root test on the cointegrating residuals for a variety of sample sizes. Given advances in computational power, it is a trivial matter to update these critical values for current use. They were constructed from a simulation experiment based on 50,000 replications under the null of no cointegration. The test statistic has a simulated five percent critical value of -6.028 . The calculated test value was -6.593 , leading us to conclude that the series do appear to be nonlinearly cointegrated (the probability value 
TABLE 1: Estimated MARS model.

\begin{tabular}{|c|c|c|c|c|}
\hline \multirow{2}{*}{$\begin{array}{l}\text { Parameter } \\
\text { Constant }\end{array}$} & \multirow{2}{*}{$\begin{array}{c}\text { Estimate } \\
8.23207\end{array}$} & \multirow{2}{*}{$\frac{\text { T-ratio }}{1525.89813}$} & \multicolumn{2}{|c|}{ Hansen stability test } \\
\hline & & & 0.044 & $(0.90)$ \\
\hline Basis function 1 & 0.83131 & 21.82990 & 0.053 & $(0.85)$ \\
\hline Basis function 2 & -0.59353 & -2.99735 & 0.016 & $(1.00)$ \\
\hline Basis function 3 & 0.39318 & 5.31771 & 0.042 & $(0.92)$ \\
\hline Basis function 4 & -0.30214 & -5.29911 & 0.029 & $(0.98)$ \\
\hline Basis function 6 & 2.33858 & 4.55403 & 0.012 & $(1.00)$ \\
\hline Basis function 8 & -6.02882 & -3.58748 & 0.088 & $(0.63)$ \\
\hline Basis function 10 & -0.73692 & -4.76604 & 0.017 & $(1.00)$ \\
\hline Hansen variance test & & & 0.163 & $(0.34)$ \\
\hline Hansen joint test & & & 1.015 & $(0.88)$ \\
\hline \multicolumn{5}{|l|}{ Basis functions } \\
\hline \multicolumn{5}{|l|}{$\mathrm{BF} 1=\max (0, \ln (\mathrm{RPDI})-8.8473)$} \\
\hline \multicolumn{5}{|l|}{$\mathrm{BF} 2=\max (0,8.8473-\ln (\mathrm{RPDI}))$} \\
\hline \multicolumn{5}{|l|}{$\mathrm{BF} 3=\max (0, \ln (\mathrm{DSR})-2.59525)$} \\
\hline \multicolumn{5}{|l|}{$\mathrm{BF} 4=\max (0,2.59525-\ln (\mathrm{DSR}))$} \\
\hline \multicolumn{5}{|l|}{$\mathrm{BF} 6=\max (0,1.46047-\ln (\mathrm{CCNR})) * \mathrm{BF} 4$} \\
\hline \multicolumn{5}{|l|}{$\mathrm{BF} 8=\max (0,1.56752-\ln (\mathrm{CCNR})) * \mathrm{BF} 1$} \\
\hline $\mathrm{BF} 10=\max (0,1.05934-\ln (\mathrm{CCR}))$ & & & & \\
\hline
\end{tabular}

RPDI, DSR, CCNR, and CCR denote real personal disposable income, the debt-service ratio, outstanding nonrevolving consumer credit, and outstanding revolving consumer credit, respectively. Estimation spans 1994 Q4 to 2008 Q3 inclusive allowing a maximum of ten basis functions and two variable interactions. The MARS sum of squared residuals based criterion function was adjusted by a penalty value of two with the dependent variable discretionary personal consumption expenditures. All series were transformed into their natural logarithms. Hansen stability tests refer to the Hansen [11] test (null: no structural change) and the associated probability values (in parentheses) for individual parameter stability, variance stability, and the hypothesis of joint stability. MARS is available at http://www.salford-systems.com/.

associated with the calculated test statistic is approximately 1.9 percent based on the simulated test values).

A second approach to testing for cointegration involves a direct examination of the error correction model, testing the statistical significance of the lagged error correction term. The null of no cointegration is not rejected if the lagged error correction term's coefficient is insignificantly different from zero. In the context of the MARS algorithm it is not clear that the statistical theory associated with the usual $t$-statistic on this error correction term actually follows the $t$ distribution because the variables in the final MARS model involve generated regressors (combinations of basis functions, variables relative to their threshold values). Palm et al. [16] provide an attractive approach to inference in this situation, developing a sieve bootstrap Wald test for noncointegration using the conditional error correction model. This model takes as its regressors the lagged changes in the predictors relative to their thresholds, as well as the lagged residual from the cointegrating regression (the so-called error correction term). The multivariate sieve bootstrap allows dependence in the series, and their test is shown to be asymptotically valid. Palm et al. [16] demonstrate that it performs well even in small samples such as those considered here. In all versions of their tests (either based on the vector error correction model or the conditional/marginal model), one rejects the null of no cointegration at about the 5 percent level of significance, further indicating the presence of nonlinear cointegration. The Palm et al. [16] test of noncointegration was also applied to the logarithms of the series in the ECM derived from the linear specification in (1). Test statistics including a constant or constant and trend were 18.402 and 13.219 , respectively, with five percent critical values well above the calculated test statistics (values ranged from 22.48 to 71.96 depending on the alternative hypothesis). At the five percent level, one does not reject the null of noncointegration in the linear specification.

The exclusion of the ACSI index from the final model does not support the view that customer satisfaction helps to predict discretionary spending. Since the model was estimated over the entire sample period, 1994 Q4 to 2008 Q3, one might be concerned with the structural stability of the estimated parameters in the final regression of discretionary spending against the basis functions. Instability may point to the need to include the ACSI index because of an "omitted variable problem." Results from the Hansen [11] stability test appear in Table 1, whence it is clear that all parameter estimates, including those of the variance of the errors, are structurally stable, both individually and jointly. Using nonlinear methods, one needs not look to customer satisfaction to predict discretionary spending.

This finding was robust across a large number of settings of the MARS routine parameters. Only when the number of basis functions as allowed to be relatively large (23) did the ACSI index play a role in the final model. In that case, 


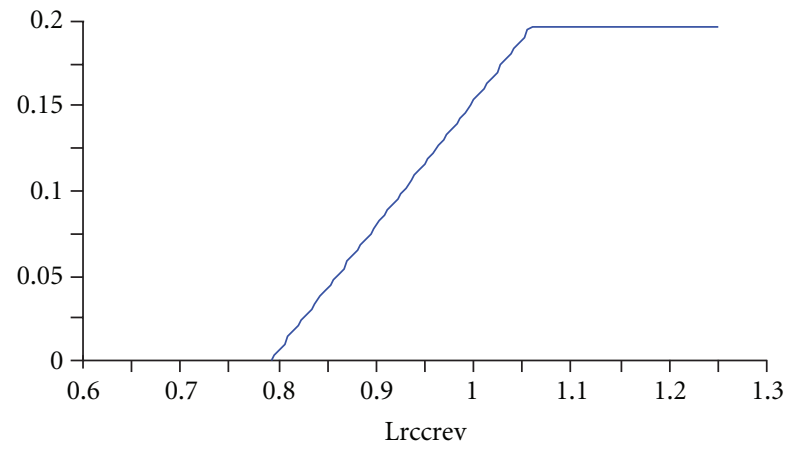

Figure 1: Revolving line of credit contribution. Curve 1: pure ordinal.

the goodness of fit of the larger model was 0.999 relative to 0.998 in the smaller model. Parsimony and the principal of Occam's razor dictate the choice of the smaller specification.

Figures 1 through 3 contain the contributions of each variable to the final fitted MARS relationship, with two views provided for each of the surface plots. Figure 1 shows that outstanding revolving consumer credit has a unique effect by itself, with values below the first knot or threshold having little effect on discretionary spending. The higher the level of revolving credit, the greater is its effect on spending, with values above the second knot having no effect (estimated using the logarithms of the series at 0.74 and 1.06, resp., or in terms of levels, \$2.09 trillion and \$2.88 trillion, resp.).

Figure 2 shows the joint contributions of the debt-service ratio and nonrevolving credit-as each series rises, so too does their contribution to spending. The second view of this figure demonstrates this interaction is strongly nonlinear. Figure 3 demonstrates that personal disposable income and nonrevolving lines of credit appear to interact directly, with higher levels raising discretionary spending.

Given the nonlinear relationship between discretionary spending and its predictors, we can estimate error correction models to determine whether any of the series is weakly exogenous. These models are linear in the parameters and involve the lagged changes in the dependent variable and the predictors relative to their estimated knots as well as the error correction term. Rather than present voluminous output, Table 2 presents the estimated speeds of adjustment coefficients-the terms on the lagged cointegrating regression terms-and their associated $t$-statistics. At the five percent level of significance, discretionary spending and revolving credit appear to respond to restore the system back to equilibrium while disposable income, the debt-service ratio, and nonrevolving credit do not move in response to disequilibria. These results are very similar to those obtained from the Johansen and Juselius [4] multivariate linear cointegration results and suggest that discretionary spending and the stock of outstanding revolving credit appear to play significant roles in reequilibrating the markets. Perhaps unfortunately, consumer satisfaction does not play an important role when one is willing to adopt nonlinear nonparametric methods to predict discretionary spending.

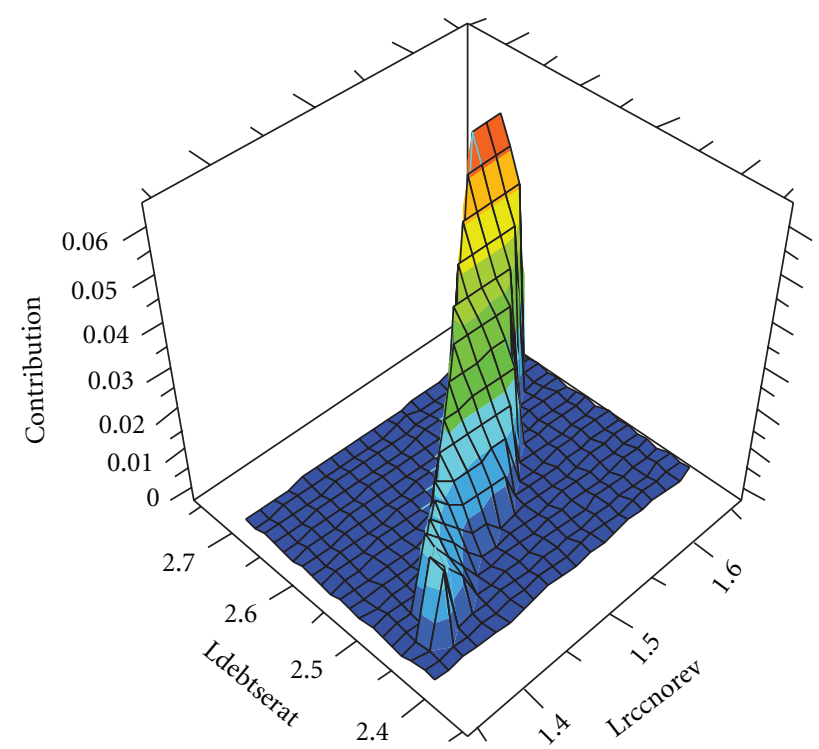

(a)

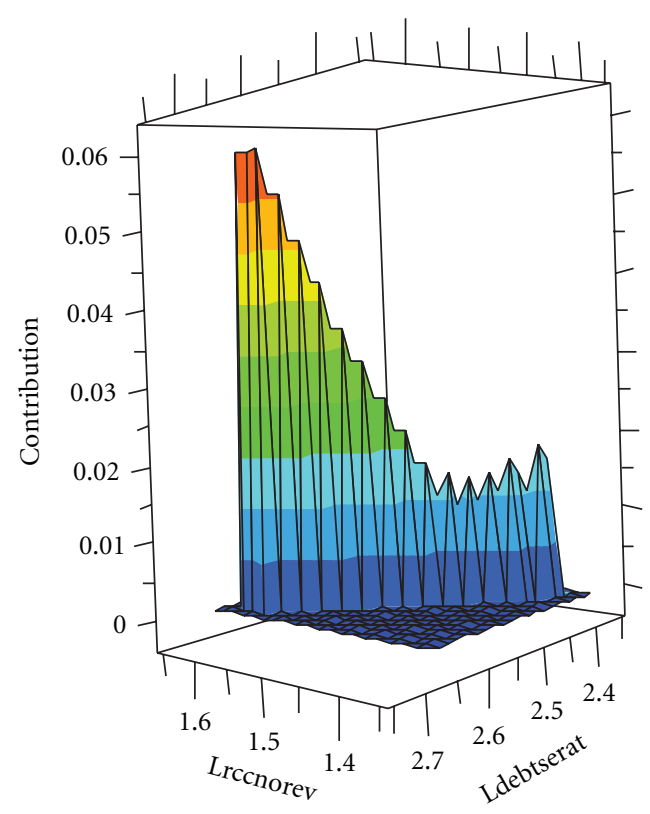

(b)

Figure 2: (a) Debt-service ratio and nonrevolving line of credit joint contribution. Surface 1: pure ordinal. (b) Debt-service ratio and nonrevolving line of credit joint contribution. Surface 1: pure ordinal.

\section{Conclusion}

The purpose here was to revisit the information in the ACSI customer satisfaction index to determine whether it should be included amongst the variables thought to affect discretionary consumption expenditures. Using single equation methods, there was little support for a link from satisfaction to spending, and this result carried through to testing for asymmetries in the relationships. When a multivariate approach to specifying a cointegrating relationship was examined, there did appear to be a stable link amongst 


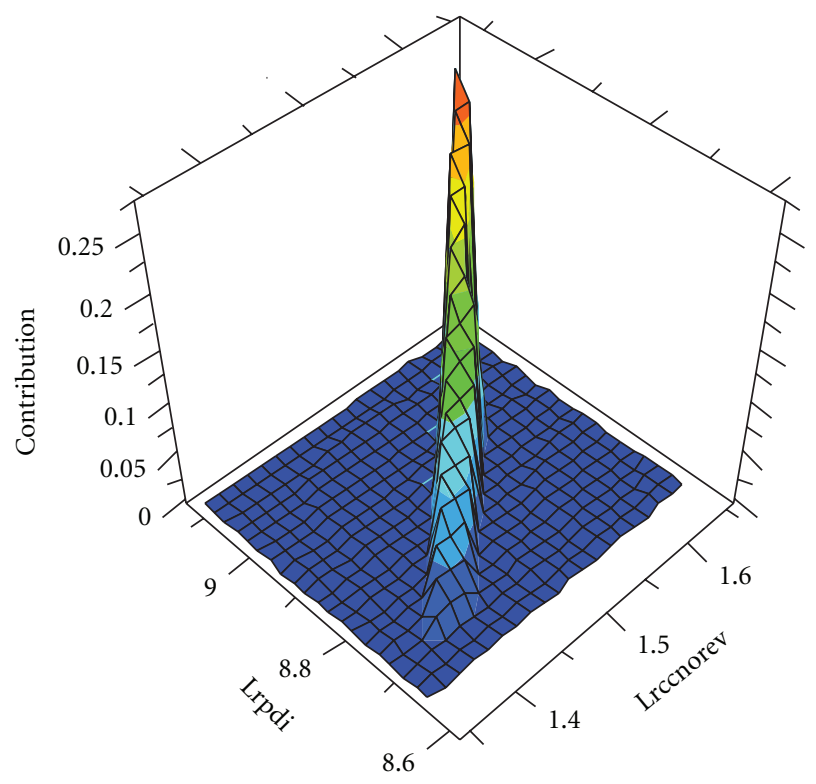

(a)

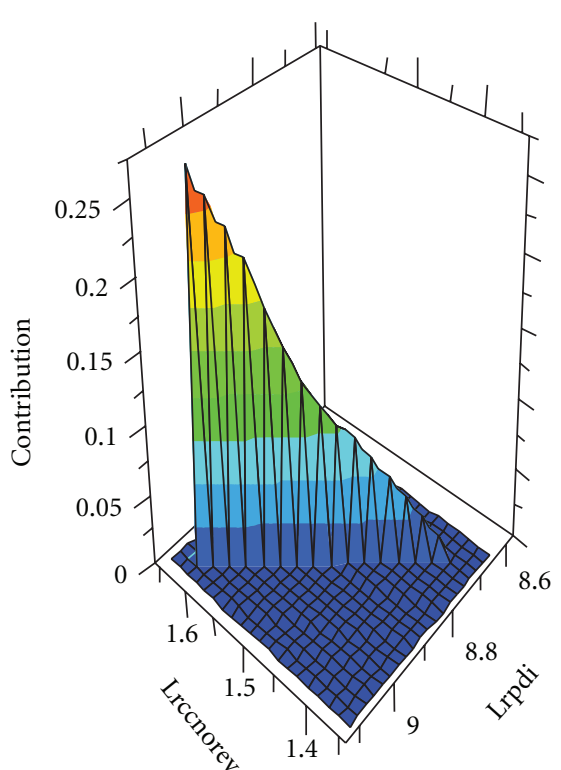

(b)

Figure 3: (a) Personal disposable income and nonrevolving line of credit joint contribution. Surface 2: pure ordinal. (b) Personal disposable income and nonrevolving line of credit joint contribution. Surface 2: pure ordinal.

TABLE 2: Error correction coefficients.

\begin{tabular}{lcc}
\hline & Coefficient & $t$-statistic \\
\hline $\begin{array}{l}\text { Real discretionary consumption } \\
\text { expenditures }\end{array}$ & -0.4940 & -2.53 \\
Real personal disposable income & 0.3387 & 1.51 \\
Revolving consumer credit & -0.3978 & -1.98 \\
Nonrevolving consumer credit & 0.1328 & 0.92 \\
Debt-service ratio & -0.1098 & -0.60 \\
\hline
\end{tabular}

Error correction model coefficients on lagged cointegrating residual from MARS model; regressions specify the change in the variable against a constant and up to three own lagged changes, and up to three lagged changes in each basis function identified by the MARS model and the lagged cointegrating regression residual. Robust standard errors using the NeweyWest covariance estimator with a lag length of two were used to construct the $t$-statistics.

the various predictors that could be used to enhance forecasts of consumer expenditures.

A nonlinear nonparametric routine failed to find evidence of interaction effects of satisfaction with any of the other predictors, all of which were shown to contribute to the temporal behavior of discretionary expenditures. This highly flexible specification provided insight into the manner in which nonrevolving consumer credit interacted with personal disposable income and the debt-service ratio, and it identified a nonlinear effect of revolving consumer credit on discretionary spending. The MARS routine failed to find a statistically significant role for customer satisfaction in modeling discretionary spending.

While perhaps somewhat discouraging, the ACSI index was not found to be an optimal predictor of discretionary spending. This suggests that future work might examine the roles that satisfaction may play in a spatially separated environment. For example, retail sales in some states may be significantly affected by measures of customer satisfaction but their net effect in economy-wide data may be difficult to identify. It may be helpful for marketing managers to examine geographically distinct areas to determine whether local economic activity is sensitive to satisfaction on a regional basis. It might also be interesting to examine whether there are industrial sensitivities to customer satisfaction that can enhance marketing strategies.

\section{References}

[1] C. Fornell, R. T. Rust, and M. G. Dekimpe, "The effect of customer satisfaction on consumer spending growth," Journal of Marketing Research, vol. 47, no. 1, pp. 28-35, 2010.

[2] S. Gupta and V. Zeithaml, "Customer metrics and their impact on financial performance," Marketing Science, vol. 25, no. 6, pp. 718-739, 2006.

[3] T. L. Keiningham, B. Cooil, L. Aksoy, T. W. Andreassen, and J. Weiner, "The value of different customer satisfaction and loyalty metrics in predicting customer retention, recommendation, and share-of-wallet," Managing Service Quality, vol. 17, no. 4, pp. 361-384, 2007.

[4] S. Johansen and K. Juselius, "Maximum likelihood estimation and inference on cointegration-with applications to the demand for money," Oxford Bulletin of Economics and Statistics, vol. 52, pp. 169-210, 1990.

[5] R. Engle and C. Granger, "Cointegration and error correction: representation, estimation and testing," Econometrica, vol. 55, pp. 251-276, 1987.

[6] M. D. Johnson, A. Herrmann, and A. Gustafsson, "Comparing customer satisfaction across industries and countries," Journal of Economic Psychology, vol. 23, no. 6, pp. 749-769, 2002. 
[7] W. Enders and P. L. Siklos, "Cointegration and threshold adjustment," Journal of Business and Economic Statistics, vol. 19, no. 2, pp. 166-176, 2001.

[8] N. S. Balke and T. B. Fomby, "Threshold cointegration," International Economic Review, vol. 38, no. 3, pp. 627-645, 1997.

[9] S. Cook, "A threshold cointegration test with increased power," Mathematics and Computers in Simulation, vol. 73, no. 6, pp. 386-392, 2007.

[10] K. Chan, "Consistency and limiting distributions of the least squares estimator of a threshold autoregressive model," The Annals of Statistics, vol. 21, pp. 520-533, 1993.

[11] B. E. Hansen, "Testing for parameter instability in linear models," Journal of Policy Modeling, vol. 14, no. 4, pp. 517-533, 1992.

[12] H. J. Bierens, "Nonparametric nonlinear co-trending analysis, with an application to inflation and interest in the U.S.," Journal of Business and Economic Statistics, vol. 18, no. 3, pp. 323-337, 2000.

[13] J. Breitung, "Rank tests for nonlinear cointegration,” Journal of Business and Economic Statistics, vol. 19, no. 3, pp. 331-340, 2001.

[14] P. S. Sephton, “Cointegration tests on MARS," Computational Economics, vol. 7, no. 1, pp. 23-35, 1994.

[15] J. Friedman, "Multivariate adaptive regression splines," Annals of Statistics, vol. 19, p. 1, 1991.

[16] F. C. Palm, S. Smeekes, and J. P. Urbain, "A sieve bootstrap test for cointegration in a conditional error correction model," Econometric Theory, vol. 26, no. 3, pp. 647-681, 2010. 


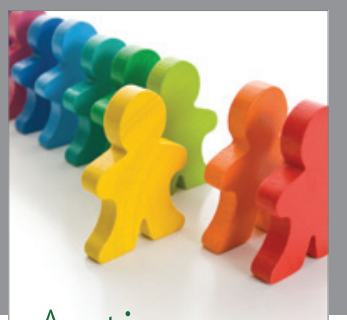

Autism

Research and Treatment
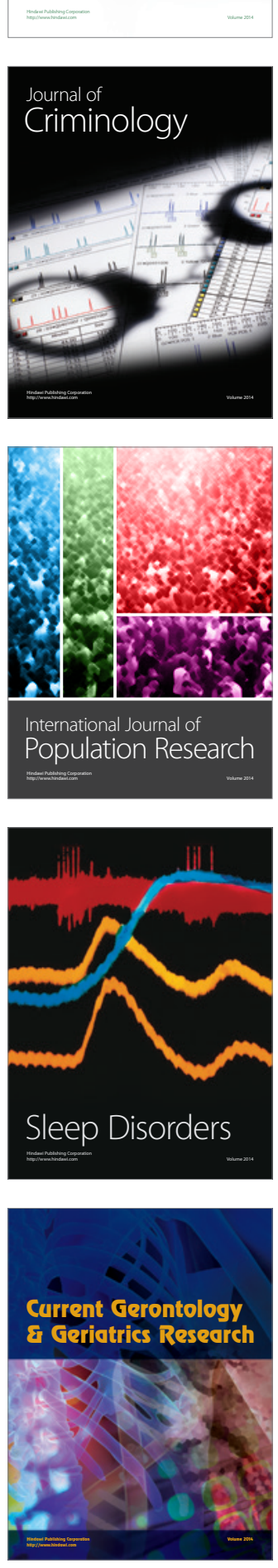
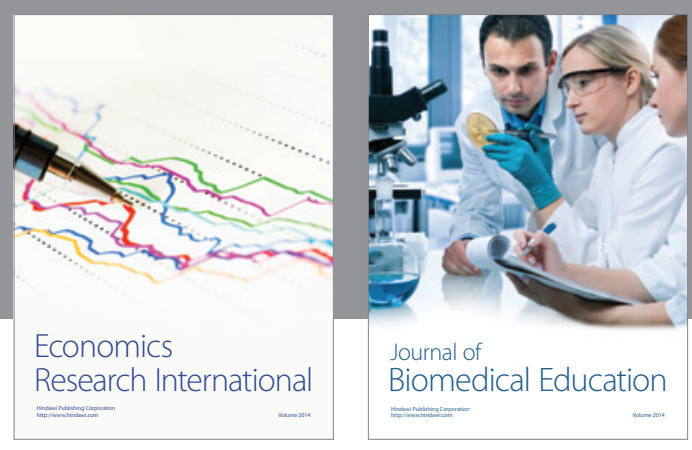

Journal of

Biomedical Education

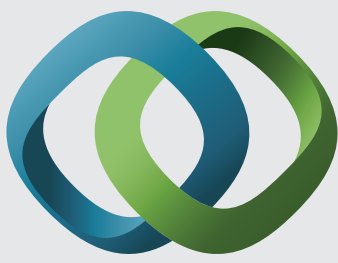

\section{Hindawi}

Submit your manuscripts at

http://www.hindawi.com
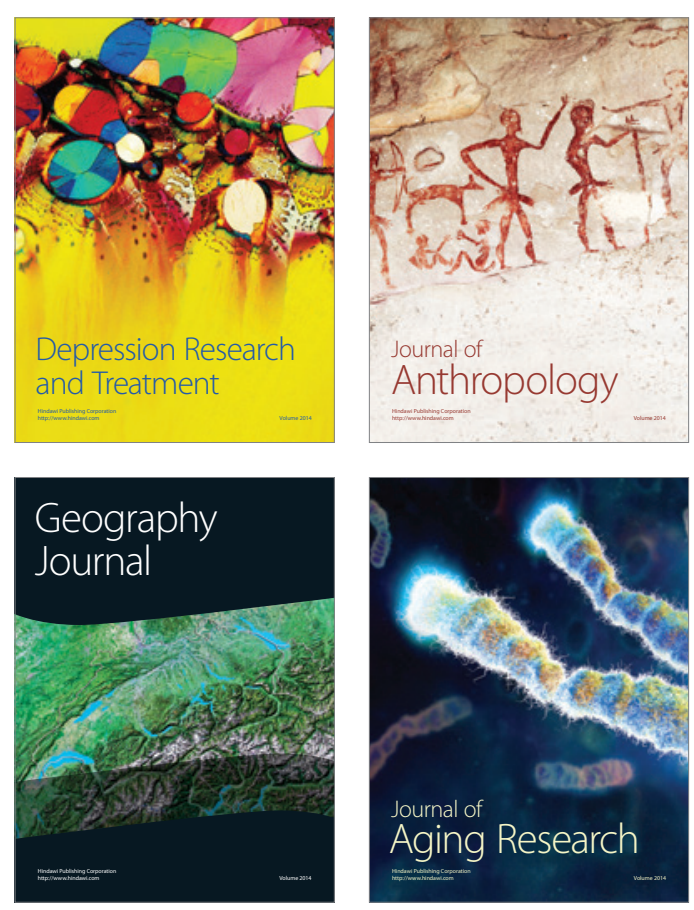

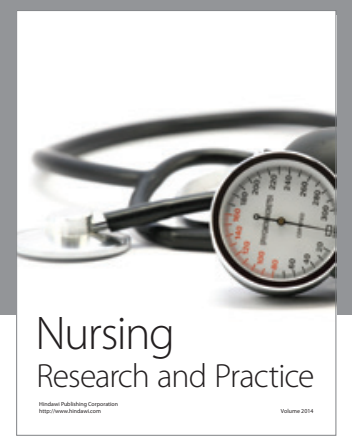

Nursing

Research and Practice

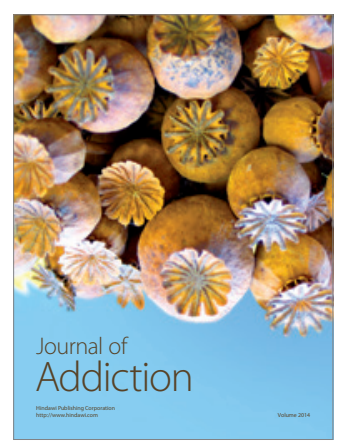

Child Development

Research

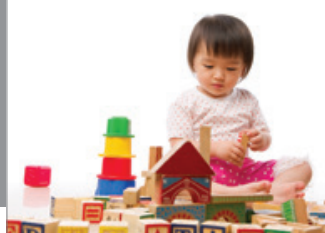

迥
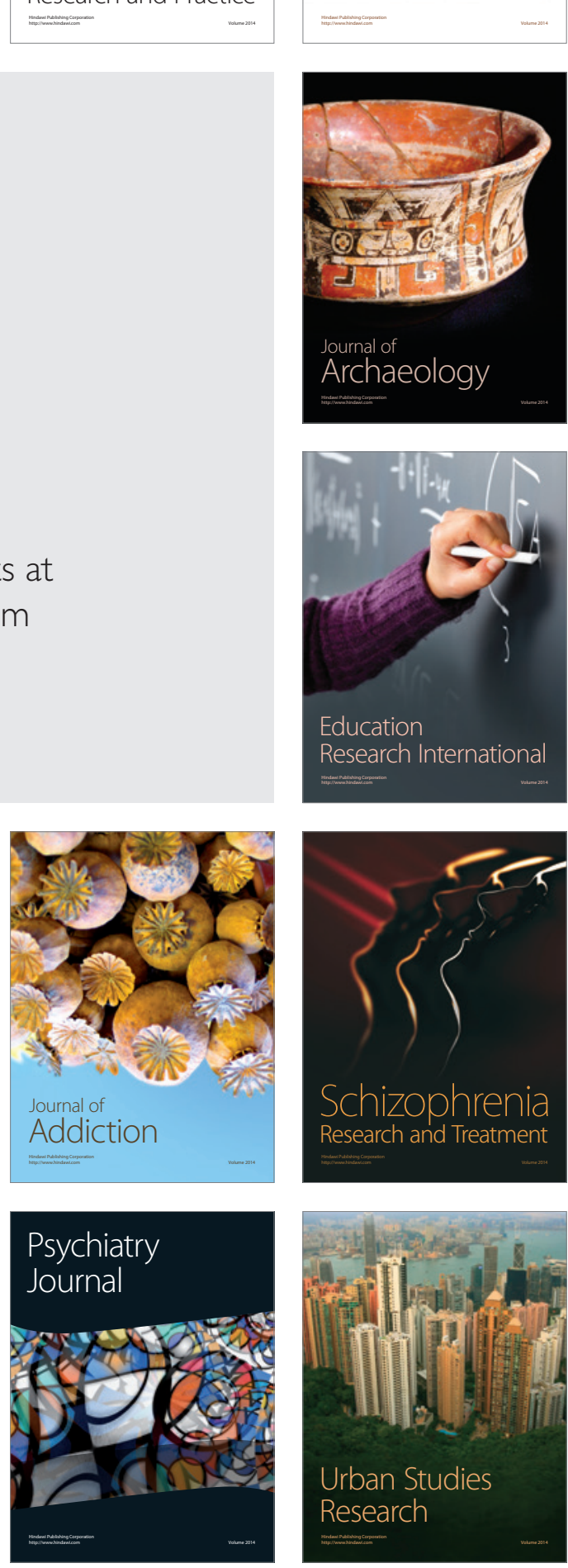